\title{
PASSOS PARA PROJETO DE PESQUISA
}

\section{Research Project Steps}

Simone REIS,UEL ${ }^{1}$

RESUMO: O presente artigo visa a facilitar a elaboração de projeto de pesquisa por iniciantes nessa atividade. Nele,são esclarecidos termos comumente confundidos, que devem ser conhecidos tão cedo possível, para própria segurança de quem busca construir conhecimento e para este próprio, quando tornado público. Também oferece definição de tipos de objetivos e interesses de pesquisa, bem como chama atenção para diferentes formas de conhecimento, suas definições, status pretendido e exemplosilustrativos. $O$ artigo se estrutura em sete partes: justificativa, objetivos, referencial teórico, metodologia, cronograma de execução, contribuições esperadas, e referências.

PALAVRAS-CHAVE: Projeto de pesquisa; interesses de pesquisa; formas de conhecimento.

ABSTRACT: This paper aims at facilitating the development of a research project by beginners in such activity. Itclarifies commonly confused terms that should be known as soon as possible, for the sake of protection of those who seek to construct knowledge and for knowledgeitself when it is made public. It also offers definition of objectives and research interests, as well as draws attention to different forms of knowledge, their definitions, their intended status, and illustrative examples. The paper is structured in seven parts: rationale, objectives, theoretical framework, methodology, implementation schedule, expected contributions, and references.

KEYWORDS: Research project, research interests, forms of knowledge.

\section{INTRODUÇÃO}

A problem well put is half solved.

(John Dewey)

A atividade de pesquisa faz parte da realidade de muitos graduandos, em especial daqueles que têm oportunidade e privilégio de realizar Iniciação Científica em suas instituições de ensino superior. Tendo em vista que tais oportunidades lhes são abertas desde o primeiro ano de seu curso, cada vez mais cedo tem sido necessário acesso à informação para se iniciar essa caminhada.

\footnotetext{
1 Professora Adjunta no Departamento de Letras Estrangeiras Modernas na Universidade Estadual de Londrina (UEL). Doutora em Ciências Sociais pela Radboud Universiteit Nijmegen (Holanda, 2005). Docente do Programa de Pós-Graduação em Estudos da Linguagem da UEL desde 2006.
} 
O presente manuscrito visa a contribuir para os iniciantes em pesquisa, oferecendo (1) passos para projeto de pesquisa (doravante PPPP), em forma de roteiro, (2) esclarecimentos sobre termos comumente confundidos por estudantes de pós-graduação, nomeadamente, área, campo, foco, perspectiva teórica, contexto, sujeitos ou participantes e unidade de análise; (3) distinção entre objetivos e interesses de pesquisa; (4) exposição de diferentes formas de conhecimento, suas definições, status pretendido de cada um, seguidos de exemplos. Trata-se de resultado de anos de trabalho como orientadora de pesquisa junto à Universidade Estadual de Londrina e também junto ao Programa de Pós-Graduação em Estudos da Linguagem, onde atuo na disciplina Metodologia de Pesquisa em Estudos da Linguagem, bem como na orientação de mestrandos e doutorandos.

Assim, este artigo se divide em sete partes. Cada uma discorre sobre um elemento do projeto de pesquisa, na ordem em que este é estruturado: justificativa, objetivos, referencial teórico, metodologia, cronograma de execução, contribuições esperadas, e referências.

\section{JUSTIFICATIVA}

O texto de justificativa da pesquisa deve explicar por que o autor/proponente do projeto considera necessário e relevante realizar o estudo. Em uma justificativa, deve-se levar em conta vários fatores. Dentre os listados abaixo, destaco os primeiros três: área, campo e foco.

1. área de inserção da pesquisa (Ex.: Linguística Aplicada; Educação; Ciências Sociais; Linguística);

2. campo (ex.: Aprendizagem; Ensino; Educação de professores; Identidade; Lexicografia);

3. foco (ex.: Bases de conhecimento do professor; Interesses humanos; Reflexão; neologismos);

4. perspectiva teórica (ex.: Refexão-sobre-ação; Teoria da ação comunicativa; etc.);

5. contexto (ex.: curso de Letras do ano 2013; colégio estadual de Londrina; região norte do Paraná);

6. sujeitos ou participantes ${ }^{2}$ (ex.: 20 alunos de Letras-Espanhol; 1 professora de inglês; 500 residentes);

7. metodologia (levantamento de dados; etnografia; pesquisa-ação; análise do discurso; método analítico indutivo-dedutivo etc.);

${ }^{2}$ CAMERON, D., et al. Introduction. In: Researching Language: Issues of power and method.London: Routledge. 1992. p. 1-28. Nesse capítulo, Cameron et al. distinguem sujeito (aquele que apenas fornece dados) de participante (aquele que realiza a pesquisa com o pesquisador, participa de modo ativo e tem poder de editar o que é será relatado como resultado da pesquisa, assim como, idealmente, participa da definição da agenda da pesquisa). 
8. unidade de análise (comportamento ${ }^{3} ;$ ação $^{4} ; \operatorname{cogniçãó}^{5} ;$ linguagem $^{6} ;$ língua $^{7} ;$ discurso $^{8}$ ). Dentre possíveis justificativas, elenco as seguintes:

1. Necessidade de desenvolver conhecimento técnico sobre o assunto. É desejável que se demonstre que falta tal conhecimento na área de pretendida inserção do trabalho;

2. Controvérsia sobre o assunto. É preciso mais pesquisas que contribuam para esclarecimento e (re)organização de tal conhecimentos, campo e área;

3. Apontamentos sobre o assunto, feitos por outros pesquisadores, oferecem perguntas de pesquisa ainda não exploradas.

4. Pioneirismo da pesquisa proposta. Para tal pretensão, é necessária comprovação de pesquisas na área e campos pretendidos, incluindo critérios das buscas realizadas junto às fontes bibliográficas.

5. Abundância de pesquisas sobre o assunto em foco. Isso justifica a possívelutilidade da pesquisa de base secundária, isto é, uma pesquisa sobre pesquisas realizadas por outros. Neste caso, o estudo será de caráter de revisão bibliográfica e sua possível contribuição deve ser em forma de metaconhecimento, por meio de síntese, apontamento de tendências, lacunas e formulação de críticas.

6. Necessidade de desenvolver conhecimento prático sobre o assunto, seja por curiosidade intelectual, seja para fins de aperfeiçoamento da prática, para o desenvolvimento de produtos com vistas a melhorar aspectos pragmáticos.

\footnotetext{
${ }^{3}$ Comportamento é o que pode ser observado. (COHEN; MANION; MORRISON, 2010).

${ }^{4}$ Ação resulta do comportamento acrescido de seu significado. Ação é contextual, pois o significado é contextualmente construído. (COHEN; MANION; MORRISON, 2010).

${ }^{5}$ Cognição "é a mobília mental abstrata que permite compreender o comportamento, a ação, o uso de língua e da linguagem e a aprendizagem humanas em determinados contextos". (REIS; VEN, 2013),

6 "Linguagem é toda forma de expressão que se realiza por vários recursos de significação, incluindo a língua (...). Inseparável do contexto e das posições sociais entre os participantes deste, a linguagem é expressão de pensamento, assim como de discurso. Neste particular, é o que estrutura a sociedade; é o instrumento de ideologia, de poder, se não estes próprios. Sua natureza é dinâmica, pois, ainda que estruture a sociedade, é também por esta estruturada." (REIS, 2013b).

${ }^{7}$ Língua "está associada, primeiramente, de modo geral, a idioma, o sistema de características relativamente duradouras e estáveis, passíveis de descrição pelas áreas componentes da Linguística, (...) que qualquer ser humano cognitivamente capaz pode adquirir em contato com a língua”. (REIS, 2013b).

${ }^{8}$ Discurso é a concepção de linguagem enquanto instrumento de poder. Na Análise do Discurso (AD), discurso é instrumento de poder. Ele é "investido pelo desejo", "carregado de terríveis poderes" (FOUCAULT, 1971/1996). Ele tem uma ordem estabelecida pelas posições sociais que os sujeitos ocupam. Os sujeitos são interditados pela ordem do discurso, isto é, seu discurso expressa aquilo que lhe é facultado dizer, levando-se em conta a estrutura social em que se inserem, estruturas essas históricas (FOUCAULT, 1971/1996),que podem se alterar ao longo do tempo. Na Análise Crítica do Discurso (ACD), o discurso "apresenta-se como uma ferramenta para a pesquisa social. Sob essa perspectiva, o uso da linguagem é discurso (Fairclough, 1992, p. 8). Este amolda e é amoldado pela sociedade, por relações e disputas de poder; ele ajuda a constituir e a mudar o conhecimento e seus objetos, as relações e identidades sociais; ele é investido de ideologias." (REIS, 2010).
} 
7. Interesses críticos do autor/proponente da pesquisa, voltados à sua própria transformação (individual) ou de grupos de pessoas (social). Neste caso, o interesse crítico pede justificativa de cunho político, típica de pesquisa que encara as relações sociais como relações de poder. A função da pesquisa, então, tem papel de crítica a situações antidemocráticas, de opressão, de desigualdade. O que justifica uma pesquisa, neste caso, é a necessidade de denúncia de distorções na realidade e de intervenção nesta para mudá-la (COHEN; MANION; MORRISON, 2010; KINCHELOE; MCLAREN, 2003).

\section{OBJETIVOS}

A escrita dos objetivos da pesquisa deve afirmar o que o autor/proponente quer com a pesquisa. Ele pode querer: conhecer, entender, comparar, discutir, tecer crítica, descrever, identificar algo (e.g. causas, pensamentos, ações, produtos, processos, consequências etc.), (des)provar teoria(s), testar hipótese(s) etc.

Os objetivos podem ser de cunhos:

1. descritivo;

2. explanatório;

3. normativo (prescritivo);

Enquanto objetivos, podem ser revestidos de interesses cognitivos (HABERMAS, 1972):

1. técnico (visando à predição e controle);

2. prático (visando à compreensão e interpretação);

3. emancipatório (visando à emancipação e liberdade).

O proponente da pesquisa pode lançar mão da combinação de um ou mais desses objetivos e interesses. O Quadro 1 possibilita ao pesquisador assinalar, simultaneamente, objetivos e interesses subjacentes ou, ainda, escrever na célula correspondente a(s) pergunta(s) de pesquisa que visa(m) a essas finalidades. 
Quadro 1: Objetivos e Interesses (OI).

\begin{tabular}{|l|l|l|l|}
\hline Interesse Objetivo & Descritivo & Explanatório & Normativo \\
\hline Técnico & & & \\
\hline Prático & & & \\
\hline Emancipatório & & & \\
\hline
\end{tabular}

Fonte: a própria autora.

Pode-se pretender produzir conhecimento em forma de princípios, máximas e normas (SHULMAN, 1986). Os princípios são as teorias e por elas uma pesquisa pode aspirar ao status de protótipo, tanto pela sua originalidade quanto pelo seu rigor, manifestos em termos de princípios teóricos. As máximas são as afirmações que não são teóricas, mas práticas, geralmente nunca foram confirmadas por pesquisa e circulam como sabedoria da prática. Elas são identificáveis em relatos denominados precedentes, porque se referem a modos de agir já realizados no passado e que são tomados como corretos. As normas, por sua vez, não são teóricas nem práticas; elas refletem valores, ideologias e dizem respeito àquilo que julgamos necessário ser incorporado e aprendido pelos professores. Expressas em texto do tipo parábola, elas revelam o que habita o coração do professor, o que guia sua prática, não porque são científicas ou práticas, mas porque são moral e eticamente corretas. No Quadro 2, esquematizoessas formulações de Shulman (1986), acrescidas de exemplos por mim elaborados. 
Quadro 2: Formas de conhecimento (FC)

\begin{tabular}{|c|c|c|c|}
\hline & \multicolumn{3}{|c|}{ FORMAS DE CONHECIMENTO } \\
\hline & Definição & $\begin{array}{c}\text { Status } \\
\text { pretendido }\end{array}$ & Exemplo ${ }^{9}$ \\
\hline Princípios & Teorias & Protótipos & $\begin{array}{c}\text { A aprendizagem carrega o } \\
\text { aspecto afetivo como impressão } \\
\text { digital. }\end{array}$ \\
\hline Máximas & $\begin{array}{c}\text { Afirmações que não são } \\
\text { teóricas, mas práticas, } \\
\text { geralmente nunca confirmadas } \\
\text { por pesquisa e circulantes como } \\
\text { sabedoria da prática. }\end{array}$ & Precedentes & $\begin{array}{l}\text { Os alunos não fazem bagunça, } \\
\text { quando a atividade em sala } \\
\text { trabalha com uma música. }\end{array}$ \\
\hline Normas & $\begin{array}{c}\text { Afirmações que não são } \\
\text { teóricas nem práticas; refletem } \\
\text { valores, ideologias sobre o que } \\
\text { julgamos necessário ser } \\
\text { incorporado e aprendido pelos } \\
\text { professores; revelam o que } \\
\text { habita o coração do professor, o } \\
\text { que guia sua prática, não } \\
\text { porque são científicas ou } \\
\text { práticas, mas porque são moral } \\
\text { e eticamente corretas. }\end{array}$ & Parábola & $\begin{array}{l}\text { O professor deve incluir música } \\
\text { em suas aulas, para que os } \\
\text { alunos gostem da matéria. }\end{array}$ \\
\hline
\end{tabular}

Fonte: a própria autora, baseada em Shulman (1986).

\footnotetext{
${ }^{9}$ Exemplos elaborados por Simone Reis.
} 
Ao final da seção de objetivos, o proponente pode apresentar as perguntas de pesquisa que o instigam à condução do estudo.

\section{REFERENCIAL TEÓRICO}

No referencial teórico, espera-se que se traga $(m)$ teoria(s) e/ou conhecimentos prévios disponíveis na literatura profissional sobre o assunto a ser pesquisado. Seu papel é apontar a contribuição da literatura na área e campo de inserção pretendidos, a fim de justificar a proposta de um novo projeto de pesquisa. Em outras palavras, conhecimento que vale a pena (HABERMAS, 1972) é, idealmente, inédito. Seria infeliz alguém realizar um estudo pensando que é relevante e inédito e, anos mais tarde, encontrar estudos precedentes sobre o mesmo tópico e desenho de pesquisa.

Felizmente, estão à disposição do pesquisador cuidadoso, bases bibliográficas eletrônicas na internet, acessíveis gratuitamente. Uma delas, de abrangência mundial denomina-se EducationResourcesInformation Center $\left(\mathrm{ERIC}^{10}\right)$. Essa base requer que as buscas sejam feitas na língua inglesa. Todavia, ela permite realizar buscas de referências de trabalhos publicados por meio de delimitação de variedade de línguas. Muitas referências são disponibilizadas pelo ERIC com texto na íntegra. O Banco de Dissertações e Teses ${ }^{11}$ da Coordenação de Aperfeiçoamento de Pessoal de Nível Superior (CAPES) também é de acesso livre, porém, esse banco oferece apenas os resumos, que podem ser acessados por delimitação de autor, ano, assunto, palavras-chave etc., na língua portuguesa, apenas.

Buscas bibliográficas eficientes demandam clareza do indagador a respeito da área, campo, foco, perspectiva teórica, contexto, sujeitos ou participantes, metodologia e unidade de análise. Em geral, as buscas se iniciam com inserção das palavras que denominam o campo e foco. Podem ser, então, refinadas com designações de contexto, unidade de análise e, por fim, perspectiva teórica. Quanto mais refinada a busca, menor será o número de referências encontradas.

Os exemplos seguintes posicionam os estudos:

1. Estudo pertencente à área de Linguística Aplicada, ao campo da identidade profissional, com foco nas bases de conhecimento do professor, sob perspectiva teórica da Análise Crítica do Discurso, em contexto de graduandos em Letras no ano de 2013, contando com uma participante, utilizando método de análise dedutivo (mais especificamente sob o aspecto Modalidade), tendo como unidade de análise o discurso.

\footnotetext{
${ }^{10} \mathrm{http}: / / \mathrm{www}$. eric.ed.gov/

${ }^{11} \mathrm{http} / / /$ capesdw.capes.gov.br/capesdw/
} 
2. Estudo da área de Linguística Aplicada, do campo da educação de professores, focalizando a aprendizagem do professor, pelas lentes teóricas da Teoria da Atividade, em contexto em-serviço, com três participantes, empregando métodos etnográficos, tendo como unidades de análise linguagem e ação.

3. Estudo inserido na Linguística Aplicada, no campo da educação de professores, focalizando crenças, sob perspectiva teórica do Conhecimento Prático Pessoal, com 20 sujeitos, método de análise indutivo-dedutiva, tendo como unidade de análise a cognição.

Idealmente, a revisão da literatura deve ser esquematizada como pirâmide invertida, partindo de afirmações relativas a contextos mais amplos e particularizando afirmações que conduzem à especificidade do tópico escolhido. A extensão de escrita do texto de referencial teórico depende da instituição a que se destina o projeto de pesquisa.

\section{METODOLOGIA}

A parte relativa à metodologia da pesquisa deve conter, minimamente, informações sobre:

1. natureza da pesquisa (se Positivista; se Qualitativa, de que tipo);

2. contexto da pesquisa;

3. sujeitos ou de participantes (número, detalhes);

4. perguntas de pesquisa (enunciadas conforme feito na seção Objetivos);

5. instrumentos de coleta de dados (incluindo piloto de instrumentos, quando necessário);

6. metodologia (positivista/ou quantitativa; qualitativa (qual tipo));

7. método(s) de análise (se indutivo; se dedutivo; se ambas as formas);

8. critérios para julgamento da qualidade da pesquisa;

9. considerações sobre ética.

\section{CRONOGRAMA DE EXECUÇÃO}

O cronograma de execução deve conter as atividades que forem pertinentes ao tipo de pesquisa em mente, a serem desenvolvidas ao longo do tempo disponível. Quando apresentado em 
forma de quadro, possibilita maior clareza e visualização das etapas do trabalho (Vide Quadro 3, em apêndice).

\section{CONTRIBUIÇÕES ESPERADAS}

Sob essa divisão, o proponente do projeto deve demonstrar coerência entre sua justificativa apresentada anteriormente, seus objetivos, consciência dos possíveis alcances e limitações da pesquisa pretendida, bem como clareza do público a quem tal estudo pode beneficiar. Em projeto de pesquisa, esta é uma seção de extensão parcimoniosa, visto que, apenas após a real condução da investigação, o autor tem elementos mais concretos para dissertar.

\section{REFERÊNCIAS}

Referências é o último tópico de um projeto de pesquisa. Trata-se de referências a tudo o que foi citado no texto do projeto.É incorreto utilizar a expressão "referências bibliográficas", pois estas podem incluir referências apenas consultadas, conhecidas, lidas, porém não citadas no texto. Por isso, o que não foi citado no texto não deve constar na lista final de Referências.

Alinha-se cada referência à esquerda, em ordem alfabética, levando-se em conta as normas de referenciação para cada tipo de fonte consultada (e.g. artigo, capítulo de livro, livro, revista ou periódico, leis, diretrizes, projetos, entrevistas, etc.). Os exemplos a seguir foram baseados nas orientações de Ribeiro (2013). A origem dos exemplos é meu acervo particular.

1. Artigo(destaque do nome da revista/periódico)

WITHAM, Shelly Anne. et al. Digging up a crime. Science Teacher. v. 71, n. 2. Arlington, Feb. 2004, p. 56-59.

Artigos de periódicos extraídos da Internet

Sem autor:

REVISTA ASAS. Perícia grafotécnica: o segredo não está nas entrelinhas. Revista Asas, Local, 16 jul. 2012. Disponível em: <http://www.asasead.net/asasEAD/?p=190> . Acesso em: 18 ago. 2013. 
2. Capítulo de livro (destaque do nome do livro do qual é parte)

ZAPF, Dieter.; EINARSEN, Ståle. Individual antecedents of bullying: victims and perpetrators. In: EINARSEN, Ståle et al. (Ed.).Bullying and emotional abuse in the workplace. London: Taylor \& Francis, 2004. p. 165-184.

ZIMBARDO, Philip George. Investigating social dynamics: power, conformity and obedience. In: TheLucifer's effect: understanding how good people turn evil. New York: The Random House Publishing Group. 2008. p. 258-296.

3. Livro (destaque do nome do livro)

BRODSKY, Caroll M. The Harassed Worker. Lexington: Lexington Books. 1976.

SEIXAS, Jacy; BRESCIANI, Stella. (Org.).Assédio moral: desafios políticos, considerações sociais, incertezas jurídicas. Uberlândia: EDUFU, 2006.

Quando for livro traduzido:

GOLDHAGEN, Daniel Jonah. Os carrascos voluntários de Hitler: o povo alemão e o Holocausto. Tradução de: Luís Sérgio Roizman. 667p. São Paulo: Cia das Letras, 1996. Título original: Hitler's willing executioners: ordinary Germans and the Holocaust.

4. Documentos ou processos produzidos por entidades coletivas (Nome da entidade em maiúsculas; destaque para o nome do documento produzido por ela).

ESCOLA NACIONAL DE SAÚDE PÚBLICA SÉRGIO AROUCA. Assédio moral no trabalho - debate. Disponível em: < http://brasil.campusvirtualsp.org/node/181336 >. Acesso em: 18 ago. 2013.

ONU. Declaração Universal dos Direitos Humanos. 1948. Disponível em: <http://www.onu.org.br/documentos/direitos-humanos/>. Acesso em 18 ago. 2013. 
5. Dissertação de Mestrado

HANUSIAK. Regiane Kowalek.Identificação da autoria de manuscritos com base em atributos genéticos e genéricos da escrita. 120fls. Dissertação (Mestrado em Informática) - Pontifícia Universidade Católica do Paraná, Curitiba. 2010.

SILVA, Cristina Rodrigues da.A Casa e o Quartel: uma análise antropológica sobre o Exército e a Família na Academia Militar das Agulhas Negras. 178fls. Dissertação (Mestrado em Antropologia Social). Universidade Federal de São Carlos, São Carlos. 2010.

6. Tese de Doutorado

WONG, Walter. Plano de Segurança para Autenticação de Dados em Redes Orientadas à Informação. 100fls. (Doutorado em Engenharia Elétrica) Universidade Estadual de Campinas, Campinas. 2011.

CAMPOS, Isabel Carolina Martins. Evidências de assédio moral e incapacidade para o trabalho. 222fls. Tese (Doutorado em Engenharia de Produção) - Universidade Federal de Santa Catarina, Florianópolis. 2011.

7. Comunicação de trabalho em evento científico (destaque do termo Anais)

NICOLALDE, Daniel Patricio; APOLINÁRIO JR, José Antonio; BISCAINHO, Luiz Wagner Pereira. Autenticação de áudio digital com base na mudança de fase da frequência da rede elétrica. In: XXVII SIMPÓSIO BRASILEIRO DE TELECOMUNICAÇÕES - SBrt, 27., 2009. Blumenau. Anais... SBrT, 2009, p. 12.

MOLL NETO, Jorge. Anatomia funcional do comportamento afiliativo e da inveja. Mesa Redonda Neurobiologia da inveja e da ternura. In: BRAZILIAN CONGRESS ON BRAIN, BEHAVIOUR AND EMOTIONS, 9., 2013. São Paulo. Anais... São Paulo: Frei Caneca Convention Center. Disponível em: <http://www.wcbbe.com/programacao/index.php>. Acesso em 18 ago. 2013. 
8. Resenha (destaque do título da resenha)

PINZANI, Alessando. Jürgen Habermas. München:C. H. Beck Verlag, 2007, 232p.

Resenha de: FELDHAUS, Charles. Jürgen Habermas. A. Pinzani. Academia Edu. Ethic@, v. 7, n. 1, p. 109-114, jun. 2008.

FREITAS, Maria Esther de; HELOANI, Roberto; BARRETO, Margarita. Assédio moral no trabalho. Local, editora, ano. Resenha de: GONDIM, Sonia Maria Guedes. Resenha do livro Assédio moral no trabalho. rPOT, v. 8, n. 2, p. 184-188, jul-dez, 2009,

9. CD-Rom

BOUTON, Alain de. Status anxiety. Ashland: Blackstoneaudio. 2006, CDROM.

10. Entrevista (destaque do título da entrevista)

REIS, Simone. Simone Reis. Entrevista concedida Freya Jensen, International Alumni Office. International Alumni Profiles. Radboud Universiteit Nijmegen, Nijmegen, 2008. Disponível em:

http://www.ru.nl/alumni/english/@703953/pagina/. Acesso em 18 ago. 2013.

11. E-mail

CIENKI, Alan. Workshop on metaphor, metonymy and multimodality. [mensagem pessoal] Mensagem recebida por <simonereiss@ gmail.com> 20 mai. 2013.

JEWITT, Carey. Details: November Video Data Analysis Group. [mensagem pessoal] Mensagem recebida por <<[endereço suprimido]>21 out. 2010.

ANDREWS, Richard.; KRESS, Gunther.; WALLACE, Katherine. Simone Reis confirmation of visiting academic status at IOE. [mensagem pessoal] Mensagem recebida por<simonereiss@ gmail.com>07 out. 2009.

TRILSBEEK, Paul. Support from the Max Planck Institute for

Psycholinguistics [mensagem pessoal] Mensagem recebida por <simonereiss@gmail.com>02 jul. 2009. 
Havendo dúvida quanto à data de uma referência, assim se procede para indicar:

[2000?] Data provável.

[200 - ] Para década certa.

[2012] Data certa, não indicada na fonte principal da obra

[19 --] Para século certo.

[18 --?] Para século provável.

Quando não houver dados da publicação relativos ao local, editora e ano, abrem-se colchetes, como nestes exemplos:

[S.1.: s.n., 19--].

[S.1.: s.n.], 1999.

São Paulo: [s.n., 19--].

Conforme considerado no início deste artigo, a atividade da pesquisa inicia-se na vida do futuro profissional da linguagem já na fase inicial de sua educação formal, em situação privilegiada, quando agraciado por uma bolsa de Iniciação Científica.

De modo, então, a contribuir para facilitar a primeira incursão de um pesquisador iniciante, o presente manuscrito ofereceu o que denominei PPPP, passos para projeto de pesquisa. Nele, esclareci termos comumente confundidos, a saber: área, campo, foco, perspectiva teórica, contexto, sujeitos ou participantes e unidade de análise. Defendi que esses termos precisam ser conhecidos com clareza, tão cedo possível, para própria segurança de quem busca construir conhecimento e para este próprio, quando tornado público. Também, ofereci o Quadro OI, para definição dos tipos de objetivos e interesses de pesquisa, e o Quadro $F C$, chamando atenção para formas de conhecimento, suas definições, status pretendido de cada um, bem como exemplos.

\section{REFERÊNCIAS}

CAMERON, Deborah et al. Introduction. In: Researching Language: Issues of power and method.London: Routledge. 1992. p. 1-28.

COHEN Louis; MANION, Lawrence; MORRISON, Keith. Research Methods in Education. London; New York: Routledge, 2010. 638p. 
HABERMAS, Jürgen. Knowledge and human interests. Tradução de Jeremy J. Shapiro. Verlag. Boston: Beacon Press, 1972. 356p. Título original: Erkenntnis und Interesse.

KINCHELOE, Joe; MCLAREN, Peter.Rethinking critical theory and qualitative research. In:

DENZIN, Norman; LINCOLN, Yvonna S. The landscape of qualitative research: theories and issues. London: SagePublications, 2003. 684p.

REIS, Simone; VEN, Piet-Hein van de. Perspectivas cognitivas na pesquisa sobre aprender a ensinar (leitura em inglês como língua estrangeira). In: SILVA, Kleber Aparecido et al. (Org.). A formação de professores de línguas: novos olhares. v. 2. Campinas: Pontes, 2013. p.107-161. REIS, Simone. Conversa com Simone Reis. In: SILVA, Kleber Aparecido; ARAGÃO Rodrigo Camargo. Conversas com formadores de professores de línguas: avanços e desafios. Campinas, SP: Pontes, 2013. p. 325-341. . Valorização do professor? Uma leitura resistente de um texto unidirecional. Linguagem \& Ensino, Pelotas, v. 13, n. 2, p. 495-523, jul-dez, 2010.

RIBEIRO, Laudicena de Fátima. Regras básicas para apresentação formal de trabalhos. Mai. 2013. Disponível em: http://www.uel.br/bc/portal/arquivos/apostila-normalizacao.pdf. Acesso em: 25 Ago. 2013.

SHULMAN, Lee S. Those who understand: Knowledge growth in teaching. Educational Researcher, v. 15, n. 2, p. 4-14, 1986. 


\section{APÊNDICE}

Quadro 3 - Cronograma de execução da pesquisa.

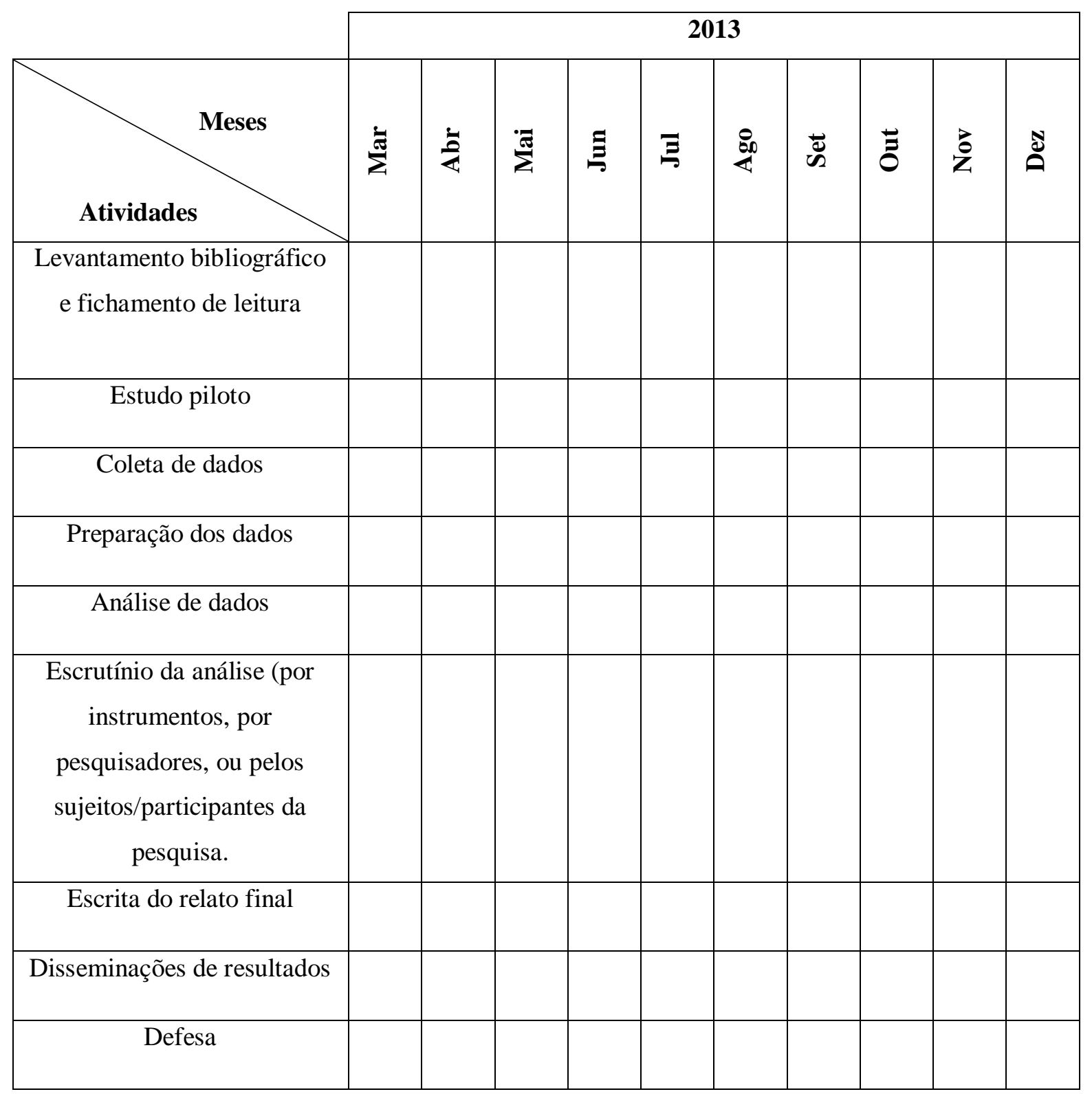

